\title{
Dynamics of a Cournot Game with Differentiated Goods and Asymmetric Cost Functions based on Relative Profit Maximization
}

\author{
Georges SARAFOPOULOS \\ Department of Economics, Democritus University of Thrace, Komotini, Greece \\ gsarafop@econ.duth.gr \\ Kosmas PAPADOPOULOS \\ Department of Economics, Democritus University of Thrace, Komotini, Greece \\ hurdlerofthrace@yahoo.gr
}

\begin{abstract}
This paper tries to investigate the complex characteristics behind quantity competition using generalized relative profit functions. For this purpose, we study the dynamics of a nonlinear Cournot-type duopoly game with differentiated goods and generalized relative profit maximization. We suppose a linear demand and asymmetric cost functions. The game is modelled with a system of two difference equations. Results concerning the equilibria of the economic model and their stability are presented and the occurrence of bifurcations is stated. We show that the model gives more complex, chaotic and unpredictable trajectories. Numerical experiments are presented.
\end{abstract}

Keywords: Cournot duopoly game; discrete dynamical system; relative profit; homogeneous expectations; stability; chaotic behaviour;

JEL Codes: C62; C72; D43;

DOI: http://doi.org/10.24818/ejis.2019.08

\section{Introduction}

An oligopoly is a market structure between monopoly and perfect competition, where there are only few firms in the market producing homogeneous products. The dynamic of an oligopoly game is more complex because firms must consider not only the behaviours of the consumers, but also the reactions of the competitors i.e. they form expectations concerning how their rivals will act. Cournot, in 1838 has introduced the first formal theory of oligopoly. He treated the case with naive expectations, so that in every step each player (firm) assumes the last values that were taken by the competitors without estimation of their future reactions.

Expectations play an important role in modelling economic phenomena. A producer can choose his expectations rules of many available techniques to adjust his production outputs. In this paper we study the dynamics of a duopoly model where each firm behaves with heterogeneous expectations strategies. We consider a duopoly model where each player forms a strategy in order to compute his expected output. Each player adjusts his outputs towards the profit maximizing amount as target by using his expectations rule. Some authors considered duopolies with homogeneous expectations and found a variety of complex dynamics in their games, such as appearance of strange attractors (Agiza, 1999; Agiza et al., 2002; Agliari et al., 2005, 2006; Bischi and Kopel, 2001; Kopel, 1996; Puu, 1998; Sarafopoulos, 2015b; Sarafopoulos et al., 2019a). Also, models with heterogeneous agents were studied (Agiza and Elsadany, 2003, 2004; Agiza et al., 2002; Den Haan, 2001; 
Fanti and Gori, 2012; Hommes, 2006; Sarafopoulos, 2015a; Sarafopoulos et al.,2017, 2018, 2019b; Tramontana, 2010; Zhang et al., 2007).

In the real market producers do not know the entire demand function, though it is possible that they have a perfect knowledge of technology, represented by the cost function. Hence, it is more likely that firms employ some local estimate of the demand. This issue has been previously analysed by Baumol and Quandt (1964), Puu (1995), Naimzada and Ricchiuti (2008), Askar (2013, 2014). Bounded rational players (firms) update their production strategies based on discrete time periods and by using a local estimate of the marginal profit. With such local adjustment mechanism, the players are not requested to have a complete knowledge of the demand and the cost functions (Agiza and Elsadany, 2004; Naimzada and Sbragia, 2006; Zhang et al., 2007; Askar, 2014). In recent years, maximizing relative profit instead of absolute profit has aroused the interest of researchers (Elsadany, 2017; Satoh and Tanaka, 2014). In this paper we introduce the concept of generalized relative profit in a Cournot - type duopoly game with differentiated goods, linear demand and asymmetric cost functions. The paper is organized as follows: In Section 2, the dynamics of the Cournot duopoly game with differentiated goods and generalized relative profit maximization is analysed. We suppose homogeneous expectations, linear demand and asymmetric cost functions. The existence and local stability of the equilibrium points are also analysed. In Section 3 numerical simulations are used to show complex dynamics via computing Lyapunov numbers, bifurcations diagrams, strange attractors and sensitive dependence on initial conditions. Finally, the paper is concluded in Section 4.

\section{The Game}

\subsection{The construction of the game}

In this Cournot-type duopoly game two firms produce differentiated goods and offer them at discrete time periods $(\mathrm{t}=0,1,2, \ldots)$ on a common market. The two firms take the decisions about their production also at discrete-time periods $(t=0,1,2, \ldots)$. In this game we consider that two players are homogeneous and more specifically, that both firms choose their production quantities in a rational way, following the same adjustment mechanism (bounded rational players). At every period $t$, each player must form an expectation of the rival's output of the next time period in order to determine the corresponding profit-maximization quantities for period $t+1$. In this study we suppose that the utility function of any player contains a percentage profit of their rival. If $\mathrm{q}_{1}, \mathrm{q}_{2}$ are the production quantities of each firm, then the inverse demand function (as a function of quantities) is given by the following equations:

$$
\mathrm{p}_{\mathrm{i}}=\alpha-\mathrm{q}_{\mathrm{i}}-\mathrm{dq}_{\mathrm{j}} \text {, with } \mathrm{i}, \mathrm{j}=1,2 \text { and } \mathrm{i} \neq \mathrm{j}
$$

where $p_{i}$ is the price of $i$ firm's product, and a is a positive parameter which expresses the market size. So, for the two players:

$$
\mathrm{p}_{1}=\alpha-\mathrm{q}_{1}-\mathrm{dq}_{2} \text { and } \mathrm{p}_{2}=\alpha-\mathrm{q}_{2}-\mathrm{dq}_{1}
$$

Also, $\mathrm{d} \in(-1,1)$ is the parameter which reveals the differentiation degree between two products. It is understood that for positive values of the parameter $d$ the larger the value, the less diversification there is between two products. If $\mathrm{d}=0$, each firm participates in a monopoly. On the other hand, negative values of this parameter describe that two products are complementary. 
We assume asymmetric cost functions for the players and more specifically, the first player uses a linear cost function:

$$
\mathrm{C}_{1}\left(\mathrm{q}_{1}\right)=\mathrm{c} \cdot \mathrm{q}_{1}
$$

and the second player a quadratic cost function:

$$
\mathrm{C}_{2}\left(\mathrm{q}_{2}\right)=\mathrm{c} \cdot \mathrm{q}_{2}^{2}
$$

(For computational purposes we use the same positive cost parameterc $>0$, which is the marginal cost of player 1 and $\mathrm{c}<\mathrm{a}$ ).

With these assumptions, the profit function for each player is:

$$
\Pi_{1}\left(\mathrm{q}_{1}, \mathrm{q}_{2}\right)=\mathrm{p}_{1} \cdot \mathrm{q}_{1}-\mathrm{C}_{1}\left(\mathrm{q}_{1}\right)=\left(\alpha-\mathrm{c}-\mathrm{q}_{1}-\mathrm{dq}_{2}\right) \cdot \mathrm{q}_{1}
$$

and

$$
\Pi_{2}\left(\mathrm{q}_{1}, \mathrm{q}_{2}\right)=\mathrm{p}_{2} \cdot \mathrm{q}_{2}-\mathrm{C}_{2}\left(\mathrm{q}_{2}\right)=\left(\alpha-\mathrm{q}_{2}-\mathrm{dq}_{1}\right) \cdot \mathrm{q}_{2}-\mathrm{cq}_{2}^{2}
$$

Then, their marginal profits at the point $\left(\mathrm{q}_{1}, \mathrm{q}_{2}\right)$ of the strategy space are given by:

$$
\frac{\partial \Pi_{1}}{\partial \mathrm{q}_{1}}=\alpha-\mathrm{c}-\mathrm{dq}_{2}-2 \mathrm{q}_{1} \quad \text { and } \quad \frac{\partial \Pi_{2}}{\partial \mathrm{q}_{2}}=\alpha-\mathrm{dq}_{1}-2(1+\mathrm{c}) \mathrm{q}_{2}
$$

Each player cares about the maximization of its utility function that contains his profit and a percentage of his rival's profits (generalized relative profit function). This utility function is described by the following equation:

$$
\mathrm{U}_{\mathrm{i}}\left(\mathrm{q}_{\mathrm{i}}, \mathrm{q}_{\mathrm{j}}\right)=\Pi_{\mathrm{i}}-\mu \cdot \Pi_{\mathrm{j}}
$$

where $\mu \in[0,1]$. For the players of this game it means that:

$$
\begin{aligned}
\mathrm{U}_{1}\left(\mathrm{q}_{1}, \mathrm{q}_{2}\right)= & \Pi_{1}-\mu \cdot \Pi_{2} \Rightarrow \frac{\partial \mathrm{U}_{1}}{\partial \mathrm{q}_{1}}=\frac{\partial \Pi_{1}}{\partial \mathrm{q}_{1}}-\mu \cdot \frac{\partial \Pi_{2}}{\partial \mathrm{q}_{1}} \Leftrightarrow \\
& \frac{\partial \mathrm{U}_{1}}{\partial \mathrm{q}_{1}}=\alpha-\mathrm{c}-2 \mathrm{q}_{1}+\mathrm{d}(\mu-1) \mathrm{q}_{2}
\end{aligned}
$$

and

$$
\begin{aligned}
\mathrm{U}_{2}\left(\mathrm{q}_{1}, \mathrm{q}_{2}\right)= & \Pi_{2}-\mu \cdot \Pi_{1} \Rightarrow \frac{\partial \mathrm{U}_{2}}{\partial \mathrm{q}_{2}}=\frac{\partial \Pi_{2}}{\partial \mathrm{q}_{2}}-\mu \cdot \frac{\partial \Pi_{1}}{\partial \mathrm{q}_{2}} \Leftrightarrow \\
& \frac{\partial \mathrm{U}_{2}}{\partial \mathrm{q}_{2}}=\alpha-2(1+\mathrm{c}) \mathrm{q}_{2}+\mathrm{d}(\mu-1) \mathrm{q}_{1}
\end{aligned}
$$

Both players follow the same strategy to decide their production quantities (homogeneous players) and they are characterized as bounded rational players. It means that they decide their productions following a mechanism that is described by the equation:

$$
\frac{\mathrm{q}_{\mathrm{i}}(\mathrm{t}+1)-\mathrm{q}_{\mathrm{i}}(\mathrm{t})}{\mathrm{q}_{\mathrm{i}}(\mathrm{t})}=\mathrm{k} \cdot \frac{\partial \mathrm{U}_{\mathrm{i}}}{\partial \mathrm{q}_{\mathrm{i}}}, \quad \mathrm{i}=1,2
$$

Through this mechanism each player increases his level of adaptation when his marginal utility is positive or decreases his level when his marginal utility is negative, where $\mathrm{k}$ is the speed of adjustment of two players, it is a positive parameter $(\mathrm{k}>0)$, which gives the extend variation production of the firm i following a given utility signal. 
The dynamical system of the players is described by:

$$
\begin{gathered}
\left\{\begin{array}{l}
\mathrm{q}_{1}(\mathrm{t}+1)=\mathrm{q}_{1}(\mathrm{t})+\mathrm{k} \cdot \mathrm{q}_{1}(\mathrm{t}) \cdot \frac{\partial \mathrm{U}_{1}}{\partial \mathrm{q}_{1}} \\
\mathrm{q}_{2}(\mathrm{t}+1)=\mathrm{q}_{2}(\mathrm{t})+\mathrm{k} \cdot \mathrm{q}_{2}(\mathrm{t}) \cdot \frac{\partial \mathrm{U}_{2}}{\partial \mathrm{q}_{2}}
\end{array} \Leftrightarrow\right. \\
\Leftrightarrow\left\{\begin{array}{l}
\mathrm{q}_{1}(\mathrm{t}+1)=\mathrm{q}_{1}(\mathrm{t})+\mathrm{k} \cdot \mathrm{q}_{1}(\mathrm{t}) \cdot\left[\alpha-\mathrm{c}-2 \mathrm{q}_{1}(\mathrm{t})+\mathrm{d}(\mu-1) \mathrm{q}_{2}(\mathrm{t})\right] \\
\mathrm{q}_{2}(\mathrm{t}+1)=\mathrm{q}_{2}(\mathrm{t})+\mathrm{k} \cdot \mathrm{q}_{2}(\mathrm{t}) \cdot\left[\alpha-2(1+\mathrm{c}) \mathrm{q}_{2}(\mathrm{t})+\mathrm{d}(\mu-1) \mathrm{q}_{1}(\mathrm{t})\right]
\end{array}\right.
\end{gathered}
$$

We investigate the effect of the parameter $\mathrm{k}$ (speed of adjustment), the parameter $\mu$ (relative profit parameter) and the parameter $d$ (differentiation degree) on the dynamics of this system.

\subsection{Dynamical analysis}

\subsubsection{The equilibriums of the game}

The equilibrium positions are the nonnegative solutions of the algebraic system:

$$
\left\{\begin{array}{l}
q_{1}^{*} \cdot \frac{\partial U_{1}}{\partial q_{1}}=0 \\
q_{2}^{*} \cdot \frac{\partial U_{2}}{\partial q_{2}}=0
\end{array}\right.
$$

which obtained by setting: $\mathrm{q}_{1}(\mathrm{t}+1)=\mathrm{q}_{1}(\mathrm{t})=\mathrm{q}_{1}^{*}$ and $\mathrm{q}_{2}(\mathrm{t}+1)=\mathrm{q}_{2}(\mathrm{t})=\mathrm{q}_{2}^{*}$ in the dynamical system of Eq.(12).

- If $\mathrm{q}_{1}^{*}=\mathrm{q}_{2}^{*}=0$, the equilibrium position is $\mathrm{E}_{0}=(0,0)$.

- If $\mathrm{q}_{1}^{*}=0$ and $\frac{\partial \mathrm{U}_{2}}{\partial \mathrm{q}_{2}}=0$, the equilibrium position is $\mathrm{E}_{1}=\left(0, \frac{\alpha}{2(1+\mathrm{c})}\right)$.

- If $\mathrm{q}_{2}^{*}=0$ and $\frac{\partial \mathrm{U}_{1}}{\partial \mathrm{q}_{1}}=0$, the equilibrium position is $\mathrm{E}_{2}=\left(\frac{\alpha-\mathrm{c}}{2}, 0\right)$.

- If $\frac{\partial \mathrm{U}_{1}}{\partial \mathrm{q}_{1}}=\frac{\partial \mathrm{U}_{2}}{\partial \mathrm{q}_{2}}=0$, we obtain:

$$
\left\{\begin{array}{l}
\alpha-c-2 q_{1}^{*}+d(\mu-1) q_{2}^{*}=0 \\
\alpha-2(1+c) q_{2}^{*}+d(\mu-1) q_{1}^{*}=0
\end{array}\right.
$$

whose solution is the Nash equilibrium

$$
E_{*}=\left(\frac{2(\alpha-c)(1+c)+\alpha d(\mu-1)}{4(1+c)-d^{2}(\mu-1)^{2}}, \frac{2 \alpha+d(\alpha-c)(\mu-1)}{4(1+c)-d^{2}(\mu-1)^{2}}\right)
$$

In the previous equilibrium we assumed:

$$
\begin{gathered}
2(\alpha-c)(1+c)+\alpha d(\mu-1)>0 \\
2 \alpha+d(\alpha-c)(\mu-1)>0
\end{gathered}
$$

and 


$$
4(1+c)-d^{2}(\mu-1)^{2}>0
$$

\subsubsection{Stability of equilibriums}

The local stability of equilibrium solutions is based on the localization on the complex plane of the eigenvalues of the Jacobian matrix of the system Eq. (13) (Gandolfo, 1997, Medio and Lines, 2001, Sedaghat, 2003). The Jacobian matrix $J\left(\mathrm{q}_{1}, \mathrm{q}_{2}\right)$ along the variable strategy $\left(\mathrm{q}_{1}, \mathrm{q}_{2}\right)$ is:

$$
J\left(\mathrm{q}_{1}, \mathrm{q}_{2}\right)=\left[\begin{array}{ll}
\mathrm{f}_{\mathrm{q}_{1}} & \mathrm{f}_{\mathrm{q}_{2}} \\
\mathrm{~g}_{\mathrm{q}_{1}} & \mathrm{~g}_{\mathrm{q}_{2}}
\end{array}\right]
$$

where:

$$
\mathrm{f}\left(\mathrm{q}_{1}, \mathrm{q}_{2}\right)=\mathrm{q}_{1}+\mathrm{k} \cdot \mathrm{q}_{1} \cdot \frac{\partial \mathrm{U}_{1}}{\partial \mathrm{q}_{1}}
$$

and

$$
g\left(q_{1}, q_{2}\right)=q_{2}+k \cdot q_{2} \cdot \frac{\partial U_{2}}{\partial q_{2}}
$$

At the Nash equilibrium:

$$
\mathrm{J}\left(\mathrm{q}_{1}^{*}, \mathrm{q}_{2}^{*}\right)=\left[\begin{array}{cc}
1+\mathrm{k} \cdot\left(\frac{\partial \mathrm{U}_{1}}{\partial \mathrm{q}_{1}}+\mathrm{q}_{1}^{*} \cdot \frac{\partial^{2} \mathrm{U}_{1}}{\partial \mathrm{q}_{1}^{2}}\right) & \mathrm{k} \cdot \mathrm{q}_{1}^{*} \cdot \frac{\partial^{2} \mathrm{U}_{1}}{\partial \mathrm{q}_{1} \partial \mathrm{q}_{2}} \\
\mathrm{k} \cdot \mathrm{q}_{2}^{*} \cdot \frac{\partial^{2} \mathrm{U}_{2}}{\partial \mathrm{q}_{2} \partial \mathrm{q}_{1}} & 1+\mathrm{k} \cdot\left(\frac{\partial \mathrm{U}_{2}}{\partial \mathrm{q}_{2}}+\mathrm{q}_{2}^{*} \cdot \frac{\partial^{2} \mathrm{U}_{2}}{\partial \mathrm{q}_{2}^{2}}\right)
\end{array}\right]
$$

At the equilibrium $\mathrm{E}_{0}$ the Jacobian matrix is:

$$
\mathrm{J}\left(\mathrm{E}_{0}\right)=\left[\begin{array}{cc}
1+\mathrm{k} \cdot(\alpha-\mathrm{c}) & 0 \\
0 & 1+\mathrm{k} \alpha
\end{array}\right] \underset{\mathrm{B}=1+\mathrm{k} \alpha}{=}\left[\begin{array}{cc}
\mathrm{A}=1+\mathrm{k} \cdot(\alpha-\mathrm{c}) \\
0 & \mathrm{~B}
\end{array}\right]
$$

with eigenvalues $r_{1}=A>1$ and $r_{2}=B>1$. Then $E_{0}$ is unstable.

At the equilibrium $\mathrm{E}_{1}$ :

$$
\mathrm{J}\left(\mathrm{E}_{1}\right)=\left[\begin{array}{cc}
1+\mathrm{k} \cdot\left[\alpha-\mathrm{c}+\mathrm{d}(\mu-1) \cdot \mathrm{q}_{2}^{*}\right] & 0 \\
\mathrm{k} \cdot \mathrm{q}_{2}^{*} \cdot \frac{\partial^{2} \mathrm{U}_{2}}{\partial \mathrm{q}_{2} \partial \mathrm{q}_{1}} & 1-\mathrm{k} \alpha
\end{array}\right] \underset{\mathrm{D}=1-\mathrm{k} \alpha}{=} \underset{\mathrm{C}=1+\mathrm{k} \cdot\left[\alpha-\mathrm{c}+\mathrm{d}(\mu-1) \cdot \mathrm{q}_{2}^{*}\right]}{=}\left[\begin{array}{cc}
\mathrm{C} & 0 \\
\mathrm{E} & \mathrm{D}
\end{array}\right]
$$


with eigenvalues $r_{1}=C$ and $r_{2}=D$. Since $r_{1}=1+k \cdot \frac{2(\alpha-c)(1+c)+\alpha d(\mu-1)}{2(1+c)}$ and $2(\alpha-c)(1+c)+\alpha d(\mu-1)>0$ (Eq. (16)), we conclude that $r_{1}>1$ and the equilibrium $E_{1}$ is unstable. For the equilibrium $\mathrm{E}_{2}$ :

$$
J\left(E_{2}\right)=\left[\begin{array}{cc}
1-\mathrm{k} \cdot(\alpha-\mathrm{c}) & \mathrm{k} \cdot \mathrm{q}_{1}^{*} \cdot \frac{\partial^{2} \mathrm{U}_{1}}{\partial \mathrm{q}_{1} \partial \mathrm{q}_{2}} \\
0 & 1+\mathrm{k} \cdot\left[\alpha+\mathrm{d}(\mu-1) \cdot \mathrm{q}_{1}^{*}\right.
\end{array}\right] \quad \begin{gathered}
\mathrm{F}=1-\mathrm{k} \cdot(\alpha-\mathrm{c}) \\
= \\
\mathrm{G}=1+\mathrm{k} \cdot\left[\alpha+\mathrm{d}(\mu-1) \cdot \mathrm{q}_{1}^{*}\right]
\end{gathered}\left[\begin{array}{cc}
\mathrm{F} & \mathrm{H} \\
0 & \mathrm{G}
\end{array}\right]
$$

with eigenvalues $r_{1}=F$ and $r_{2}=G$. Since $r_{2}=1+k \cdot\left[\frac{2 \alpha+d(\alpha-c)(\mu-1)}{2}\right]$ and $2 \alpha+\mathrm{d}(\alpha-\mathrm{c})(\mu-1)>0$ (Eq. (17)), we conclude that $r_{2}>1$ and the equilibrium $\mathrm{E}_{2}$ is unstable.

To study the local stability of the Nash equilibrium we recall the well-known conditions of stability which depend on the trace (T) and the determinant (D) of the Jacobian matrix. For a discrete time system in two dimensions the eigenvalues of the Jacobian is inside the unit circle of the complex plane if and only if the following conditions are verified:

$$
\begin{array}{cc}
\text { (i) } & 1-\mathrm{D}>0 \\
\text { (ii) } & 1-\mathrm{T}+\mathrm{D}>0 \\
\text { (iii) } & 1+\mathrm{T}+\mathrm{D}>0
\end{array}
$$

(Gandolfo, 1997; Medio and Gallo, 1995; Elaydi, 2005).

From condition (ii) we obtain:

$$
1-\mathrm{T}+\mathrm{D}>0 \Leftrightarrow\left[4(1+\mathrm{c})-\mathrm{d}^{2}(\mu-1)^{2}\right] \mathrm{k}^{2} \mathrm{q}_{1}^{*} \mathrm{q}_{2}^{*}>0
$$

and this condition is always satisfied $\left(4(1+\mathrm{c})-\mathrm{d}^{2}(\mu-1)^{2}>0\right.$ Eq.(18)).

From the first condition (i) we obtain:

$$
\begin{gathered}
1-\mathrm{D}>0 \Leftrightarrow \\
\Leftrightarrow 2 \mathrm{q}_{1}^{*}+2(1+\mathrm{c}) \mathrm{q}_{2}^{*}-\left[4(1+\mathrm{c})-\mathrm{d}^{2}(\mu-1)^{2}\right] \mathrm{kq}_{1}^{*} \mathrm{q}_{2}^{*}>0
\end{gathered}
$$

Finally, from condition (iii) we obtain:

$$
\begin{gathered}
1+\mathrm{T}+\mathrm{D}>0 \Leftrightarrow \\
\Leftrightarrow\left[4(1+\mathrm{c})-\mathrm{d}^{2}(\mu-1)^{2}\right] \mathrm{q}_{1}^{*} \mathrm{q}_{2}^{*} \cdot \mathrm{k}^{2}-4\left[\mathrm{q}_{1}^{*}+(1+\mathrm{c}) \mathrm{q}_{2}^{*}\right] \mathrm{k}+4>0
\end{gathered}
$$

From the previous analysis the following proposition is obtained: 


\section{Proposition:}

The Nash equilibrium of the discrete dynamical system Eq. (13) is locally asymptotically stable if:

$$
2 q_{1}^{*}+2(1+c) q_{2}^{*}-\left[4(1+c)-d^{2}(\mu-1)^{2}\right] k q_{1}^{*} q_{2}^{*}>0
$$

and

$$
\left[4(1+c)-d^{2}(\mu-1)^{2}\right] q_{1}^{*} q_{2}^{*} \cdot k^{2}-4\left[q_{1}^{*}+(1+c) q_{2}^{*}\right] k+4>0
$$

Consequences:

- From the first condition we obtain:

$$
0<\mathrm{k}<\frac{1}{4(1+\mathrm{c})-\mathrm{d}^{2}(\mu-1)^{2}} \cdot\left(\frac{2}{\mathrm{q}_{2}^{*}}+\frac{2(1+\mathrm{c})}{\mathrm{q}_{1}^{*}}\right) \quad \text { (First stability condition for } \mathrm{k} \text { ) (30) }
$$

- The discriminant of Eq. (29) is positive:

$$
\Delta=16\left[\mathrm{q}_{1}^{*}-(1+\mathrm{c}) \mathrm{q}_{2}^{*}\right]^{2}+16 \mathrm{~d}^{2}(\mu-1)^{2} \mathrm{q}_{1}^{*} \mathrm{q}_{2}^{*}>0 \text {, with } \mathrm{q}_{1}^{*}, \mathrm{q}_{2}^{*} \neq 0
$$

Consequently, the second condition is true if and only if

$$
\mathrm{k} \in\left(0, \mathrm{k}_{1}\right) \cup\left(\mathrm{k}_{2},+\infty\right) \quad(\text { Second stability condition for } \mathrm{k})
$$

where

$$
\mathrm{k}_{1,2}=\frac{4\left[\mathrm{q}_{1}^{*}+(1+\mathrm{c}) \mathrm{q}_{2}^{*}\right] \pm \sqrt{\Delta}}{2\left[4(1+\mathrm{c})-\mathrm{d}^{2}(\mu-1)^{2}\right] \mathrm{q}_{1}^{*} \mathrm{q}_{2}^{*}}
$$

are the two real roots of Eq.(29).

\section{Numerical Simulations}

\subsection{Stability spaces}

The 3D stability space (Figure 1) includes the main three parameters that is the parameters $\mathrm{k}$ (speed of adjustment), $\mathrm{d}$ (the differentiation degree between two products) and $\mu$ (relative profit parameter). This three-dimensional space is obtained by the two stability conditions that are described in the previous proposition, setting specific values for the other parameters $(\mathrm{a}=5$ and $\mathrm{c}=1)$. Figure 2 contains the stability space between the parameters $\mu$ (horizontal axis) and d (vertical axis), which is obtained by the two stability conditions with $\mathrm{k}=0.405$. 
Figure 1. 3D stability space between the parameters $k, d$ and $\boldsymbol{\mu}$ for $a=5, c=1$.

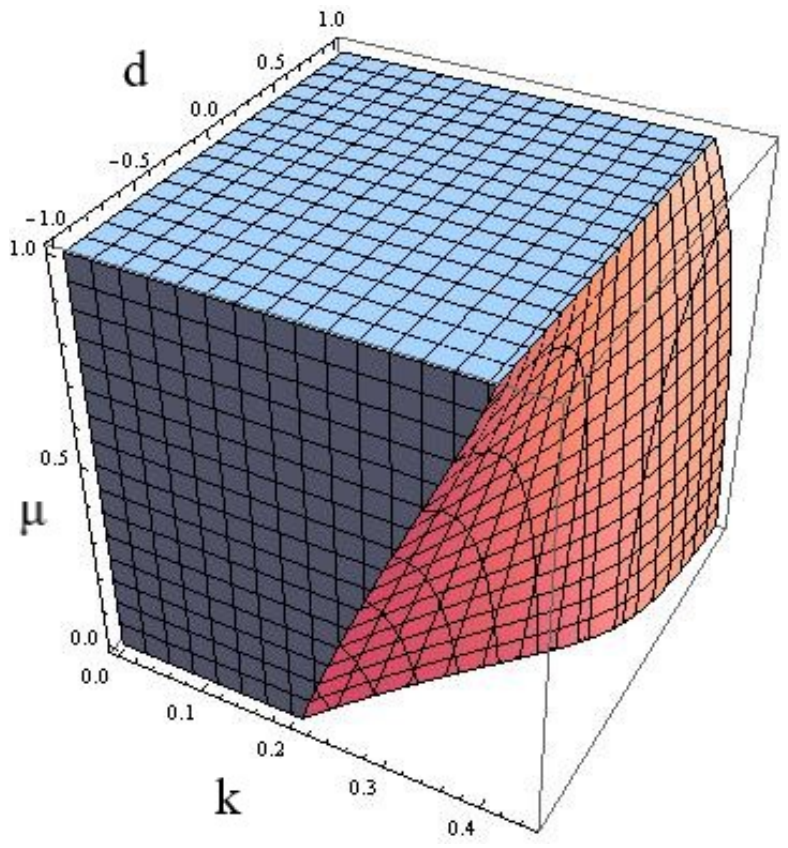

Figure 2. Region of stability between $\mu$ (horizontal axis) and $d$ (vertical axis) for $\mathrm{a}=5, \mathrm{c}=1, \mathrm{k}=\mathbf{0 . 3 9}$

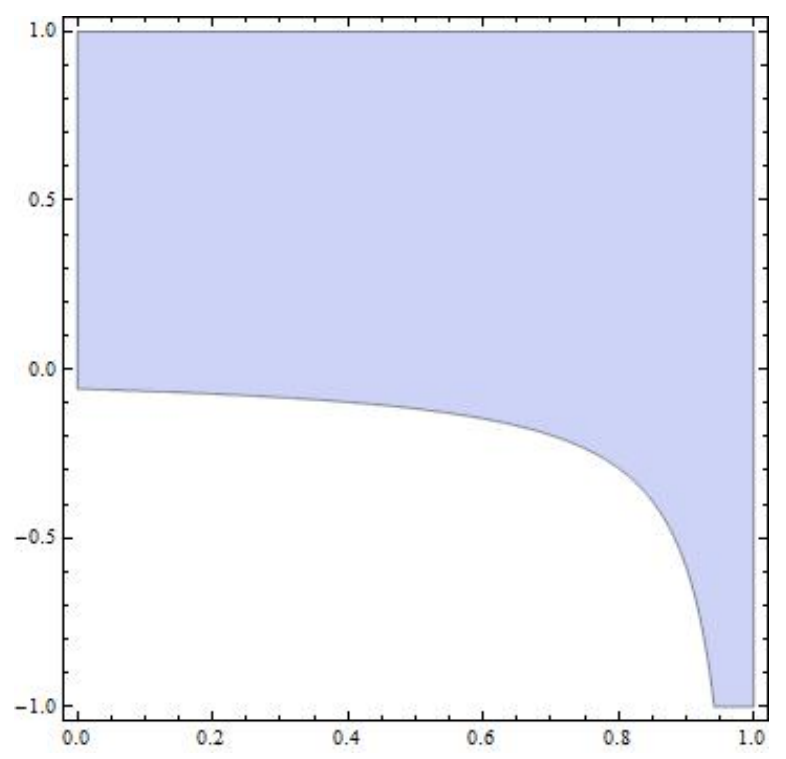

Figure 3 contains the stability space between the parameters $\mathrm{k}$ (horizontal axis) and $\mu$ (vertical axis) which is obtained by the two stability conditions with for $\mathrm{a}=5, \mathrm{c}=1$ and $\mathrm{d}=0.5$ The last stability space (Figure 4 ) is between the parameters $\mathrm{k}$ (horizontal axis) and $\mathrm{d}$ (vertical axis) for $\mathrm{a}=5, \mathrm{c}=1$ and $\mu=0.7$ 
Figure 3. Region of stability between $k$ (horizontal axis) and $\mu$ (vertical axis) for $a=5, c=1, d=0.5$

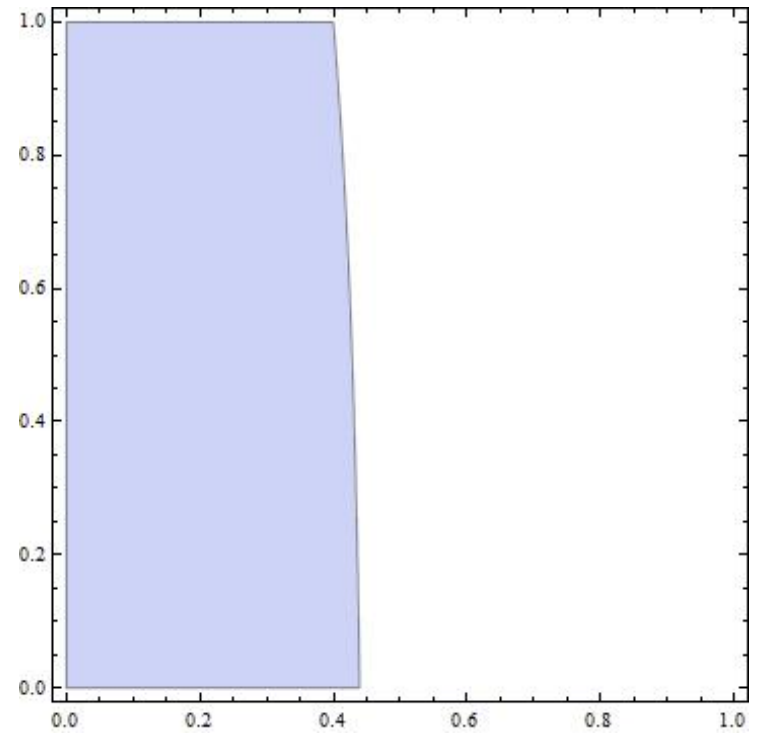

Figure 4. Region of stability between $k$ (horizontal axis) and $d$ (vertical axis) for $\mathrm{a}=5, \mathrm{c}=\mathbf{1}, \mu=0.1$

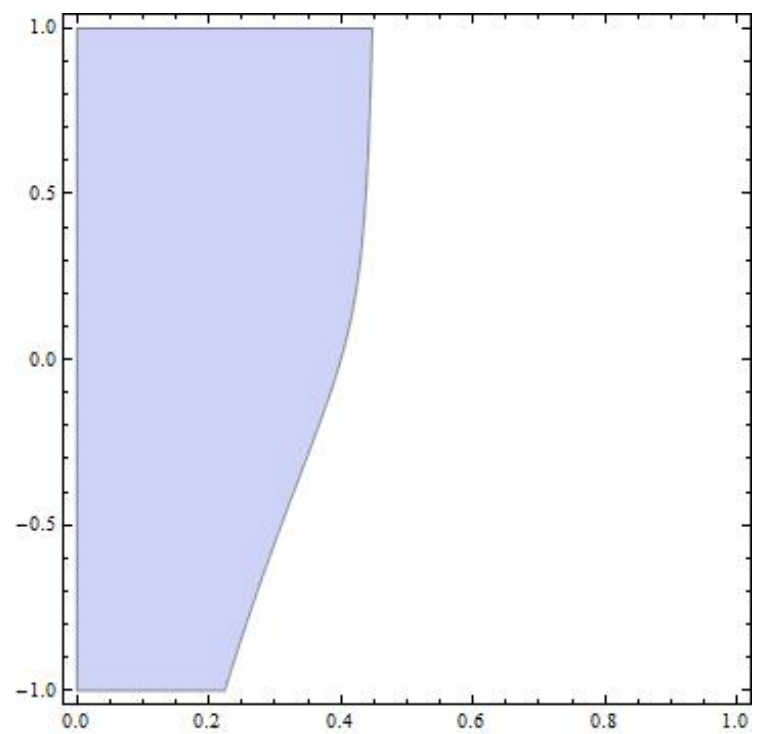

3.2. Effect of the parameter $k$ (speed of adjustment) on the dynamics of the system Eq. (13).

In this section we present various numerical results focusing on the parameter $\mathrm{k}$, including bifurcation diagrams, strange attractors, Lyapunov numbers and sensitive dependence on initial conditions (Kulenovic and Merino, 2002; Medio and Gallo, 1995). For this reason, we choose to set some fixed values to other parameters as: $a=5, c=1, d=0.5$ and $\mu=0.7$. As a result, we find that $\mathrm{q}_{1}^{*} \simeq 1.91$ and $\mathrm{q}_{2}^{*} \simeq 1.18$. Now, it's easy to form the stability conditions:

$$
0<\mathrm{k}<0.47 \text { and } \mathrm{k} \in(0,0.41) \cup(0.53,+\infty)
$$

the final stability condition is exported by the common solutions of these above inequalities and they are described as: $k \in(0,0.41)$. It is verified by the bifurcation diagrams of the parameter $\mathrm{k}$ against the variables $\mathrm{q}_{1}^{*}$ (left) and $\mathrm{q}_{2}^{*}$ (right) that are shown in Figure 5 and 
Figure 6. These two figures show that the equilibrium undergoes a flip bifurcation at $\mathrm{k}=0.41$. Then a further increase in speed of adjustment implies that a stable two-period cycle emerges for $0.41<\mathrm{k}<0.50$. As long as the parameter $\mathrm{k}$ reduces a four-period cycle, cycles of highly periodicity and a cascade of flip bifurcations that ultimately lead to unpredictable (chaotic) motions are observed when $\mathrm{k}$ is larger than 0.54 .

Figure 5. Bifurcation diagrams with respect to the parameter $k$ against the variables $q_{1}$ (left) and $q_{2}$ (right) with 400 iterations of the map Eq.(13) for $a=5$, $c=1, d=0.5$ and $\mu=0.7$
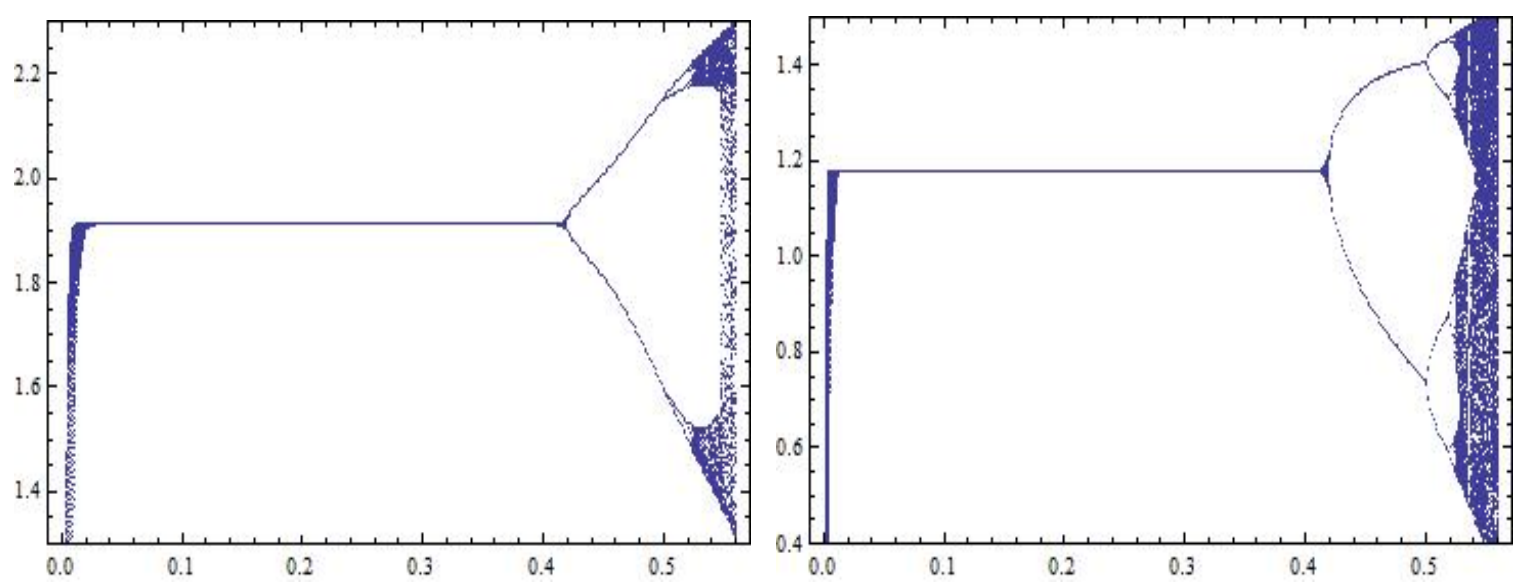

Figure 6. Two bifurcation diagrams of Fig.5 are plotted in one

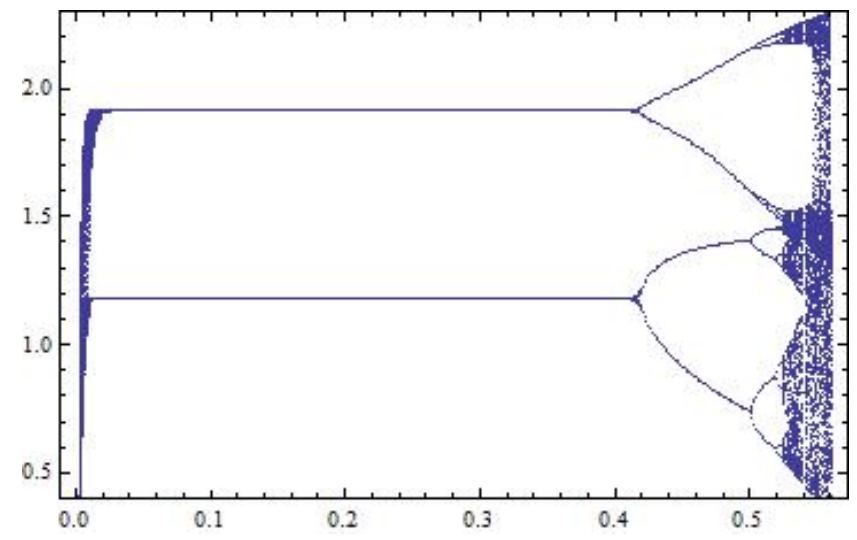

As a product of the motion characteristics in chaotic system, strange attractor reflects a form of disorder steady state of the chaos. The strange attractor and initial condition sensitivity, as the two main characteristics of chaos, reveal some inherent characteristics of the system in the chaotic state. This unpredictable (chaotic) behaviour of the system Eq. (13) is visualized in Figure 7 (left) with the strange attractor for $\mathrm{k}=0.58$. This is the graph of the orbit of $(0.1,0.1)$ with 8000 iterations of the map Eq. (13) for $a=5, c=1, d=0.5$ and $\mu=0.7$. Also, we use the useful tool of Lyapunov numbers (Figure 7 (right)) (i.e. the natural logarithm of Lyapunov exponents) as a function of the parameter of interest. Figure 7 (right) shows the Lyapunov numbers of the same orbit. It is known that if the Lyapunov number is greater than 1 , one has evidence for chaos. 
Figure 7. Phase portrait (strange attractor) (left) and Lyapunov numbers (right) of the orbit of $(0.1,0.1)$ with 8000 iterations of the map Eq.(13) for $a=5$, $\mathrm{c}=1, \mathrm{~d}=0.5, \mu=0.7$ and $\mathrm{k}=0.58$
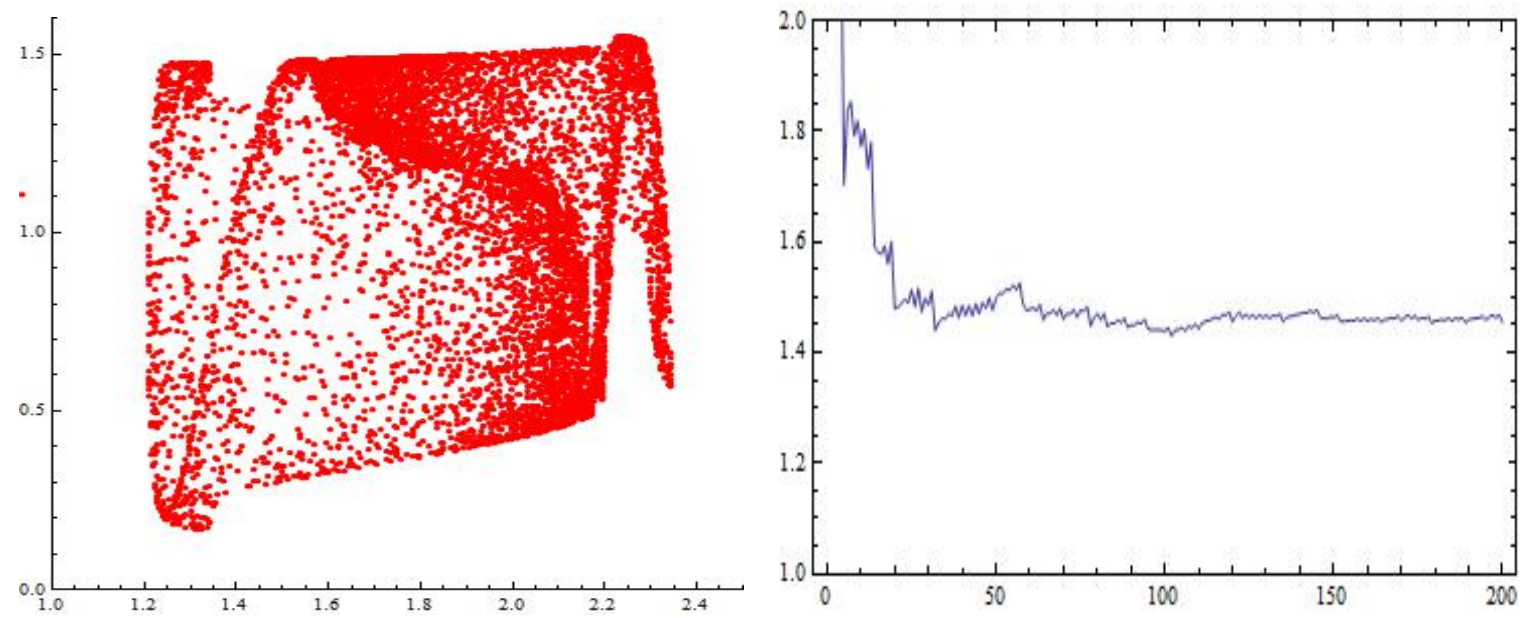

Another characteristic of deterministic chaos is the sensitivity dependence on initial conditions. In order to show the sensitivity dependence on initial conditions of the system Eq. (13), we have computed two orbits with initial points $(0.1,0.1)$ and $(0.101,0.1)$ respectively. Figure 8 shows the sensitivity dependence on initial conditions for $\mathrm{q}_{1}-$ coordinate of the two orbits, for the system Eq.(13), plotted against the time with the parameter values $\mathrm{a}=5, \mathrm{c}=1, \mathrm{~d}=0.5$ and $\mu=0.7$ and $\mathrm{k}=0.58$. At the beginning the time series are indistinguishable; but after a number of iterations, the difference between them builds up rapidly. From these numerical results when all parameters are fixed and only $k$ is varied the structure of the game becomes complicated through period doubling bifurcations, more complex bounded attractors are created which are aperiodic cycles of higher order or chaotic attractors.

Figure 8. Sensitive dependence on initial conditions for $q_{1}$ - coordinate plotted against the time: the orbit of $(0.1,0.1)$ (left) and the orbit of $(0.101,0.1)$ (right) of the system Eq. (13) for $a=5, c=1, d=0.5, \mu=0.7$ and $k=0.58$
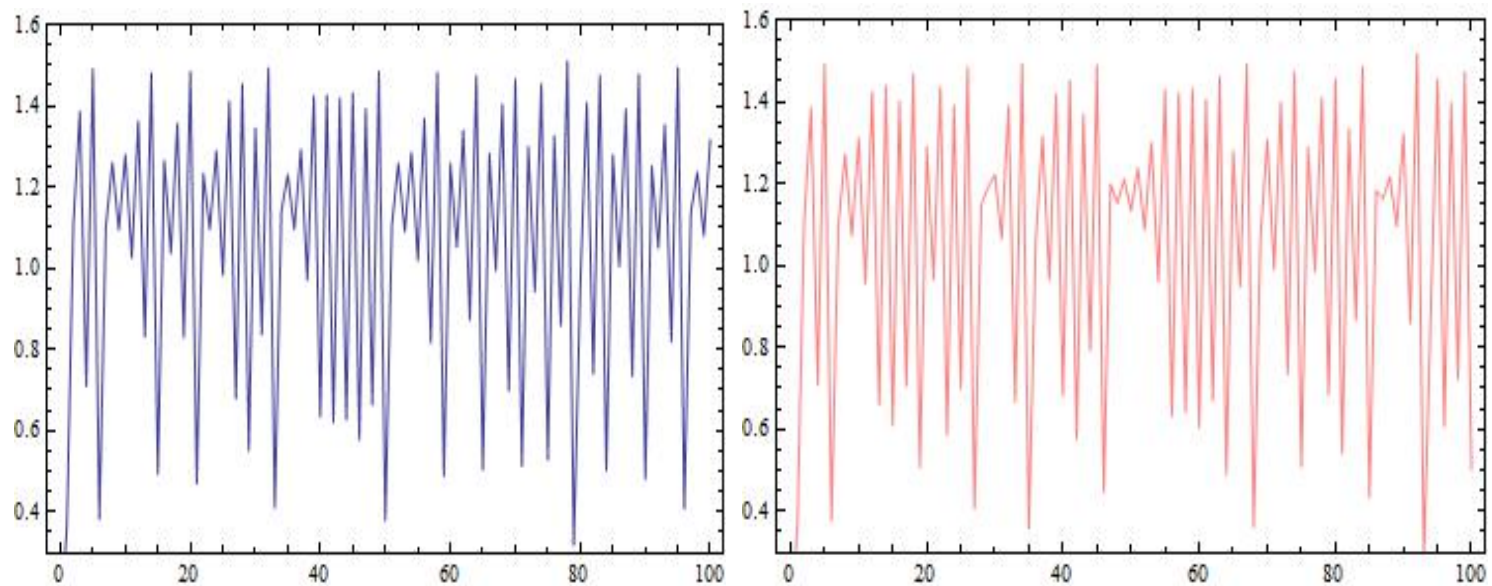

3.3. Effect of the parameter $d$ (product differentiation degree).

The effect of the parameter $d$ on the dynamics of the system Eq. (13) and the unpredictable behaviour of this system is visualized in the next figures. Using the Figure 4 we can find that when $\mu=0.1$ and $\mathrm{k}=0.43$ there is a stable equilibrium for $\mathrm{d} \in(0.5,1)$ and it is verified by the bifurcation diagrams of $d$ against $\mathrm{q}_{1}$ (left) and $\mathrm{q}_{2}$ (right) (Figures 9 and 10). Also, 
a chaotic behaviour for the system Eq. (13) appears for negative values of the parameter $\mathrm{d}$ (products' differentiation degree) making the system unpredictable.

Figure 9. Bifurcation diagrams with respect to the parameter $d$ against the variables $q_{1}$ (left) and $q_{2}$ (right) with 400 iterations of the map Eq. (13) for $a=5$, $c=1, k=0.43$ and $\mu=0.1$
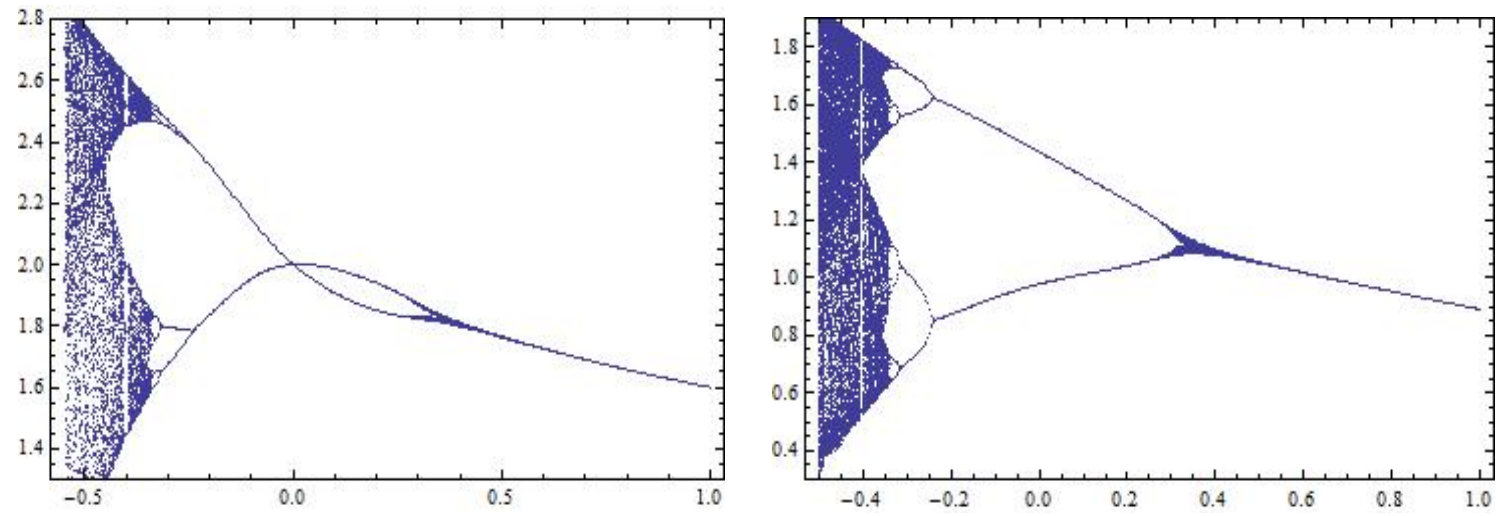

Figure 10. Two bifurcation diagrams of Figure 9 are plotted in one

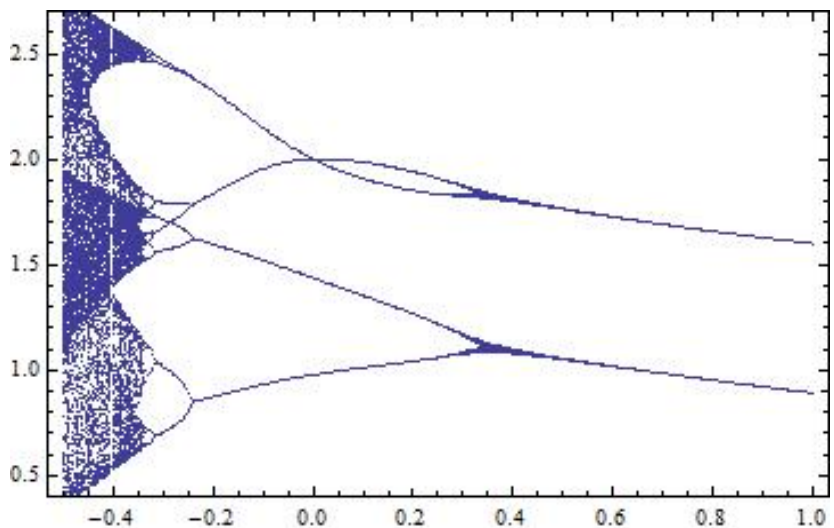

This chaotic behaviour can be shown by the strange attractor (Figure 11 (left)) and the Lyapunov numbers (Figure 11 (right)) that are plotted for $\mathrm{d}=-0.5$.

Figure 11. Phase portrait (strange attractor) (left) and Lyapunov numbers (right) of the orbit of $(0.1,0.1)$ with 2000 iterations of the map Eq. (13) for $a=5$, $\mathrm{c}=1, \mathrm{k}=0.43, \mu=0.1$ and $\mathrm{d}=-\mathbf{0 . 5}$
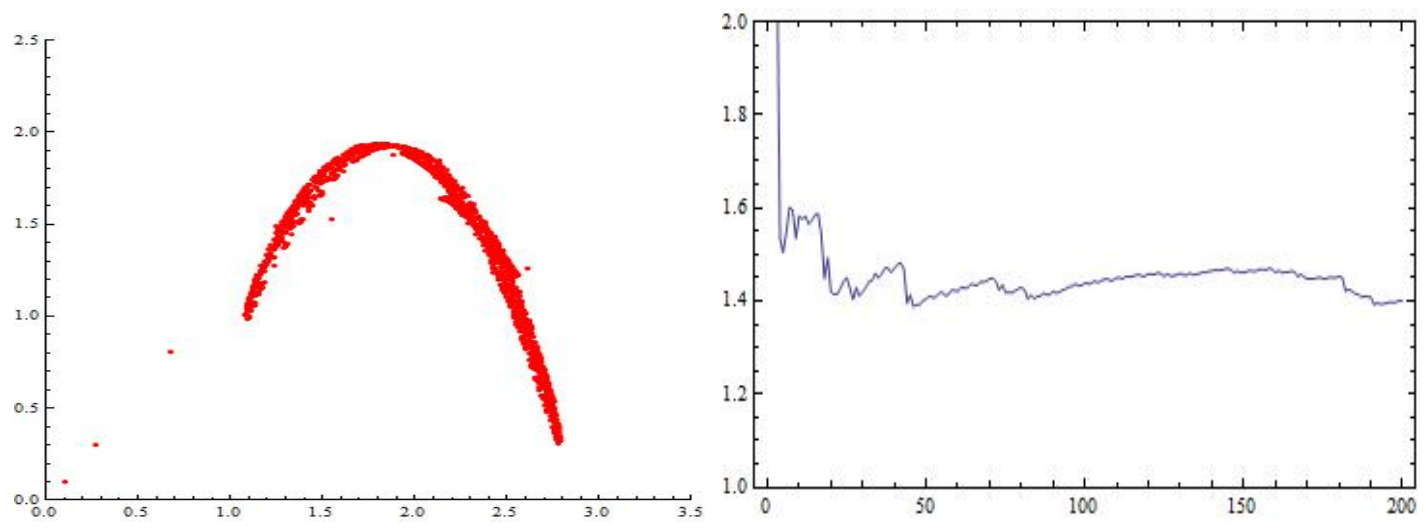

Finally, the system Eq. (13) becomes sensitive on small changes of its initial conditions when the parameter $d$ takes small negative values (Figure 12). 
Figure 12: Sensitive dependence on initial conditions for $\mathrm{q}_{1}$-coordinate plotted against the time: the orbit of $(0.1,0.1)$ (left) and the orbit of $(0.101,0.1)$ (right) of the system Eq. (13) for $a=5, c=1, k=0.43, \mu=0.1$ and $d=-0.5$
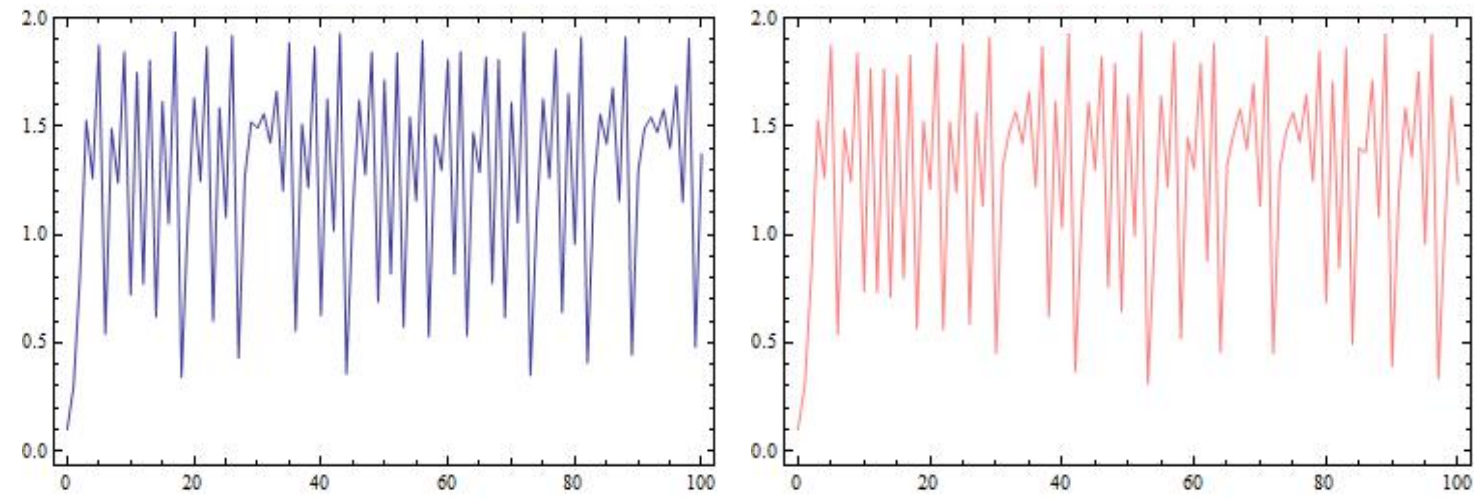

3.4. Effect of the parameter $\mu$ (relative profit parameter)

In this game the parameter $\mu$ reveals the percentage of the rival's profit is taking account by each player. The effect of the parameter $\mu$ on the dynamics of the system Eq. (13) and the unpredictable behaviour of this system is visualized in the next figures. For example, if $\mathrm{a}=5, \mathrm{c}=1, \mathrm{k}=0.39, \mathrm{~d}=-0.6$ complexity appears for very small values of the parameter $\mu$. The bifurcation diagrams of the parameter $\mu$ against the variables $\mathrm{q}_{1}^{*}$ (left) and $\mathrm{q}_{2}^{*}$ (right) are shown in Figure 13 and Figure 14.

Figure 13. Bifurcation diagrams with respect to the parameter $\mu$ against the variables $q_{1}$ (left) and $q_{2}$ (right) with 400 iterations of the map Eq. (13) for $a=5$, $c=1, k=0.39$ and $d=-0.6$
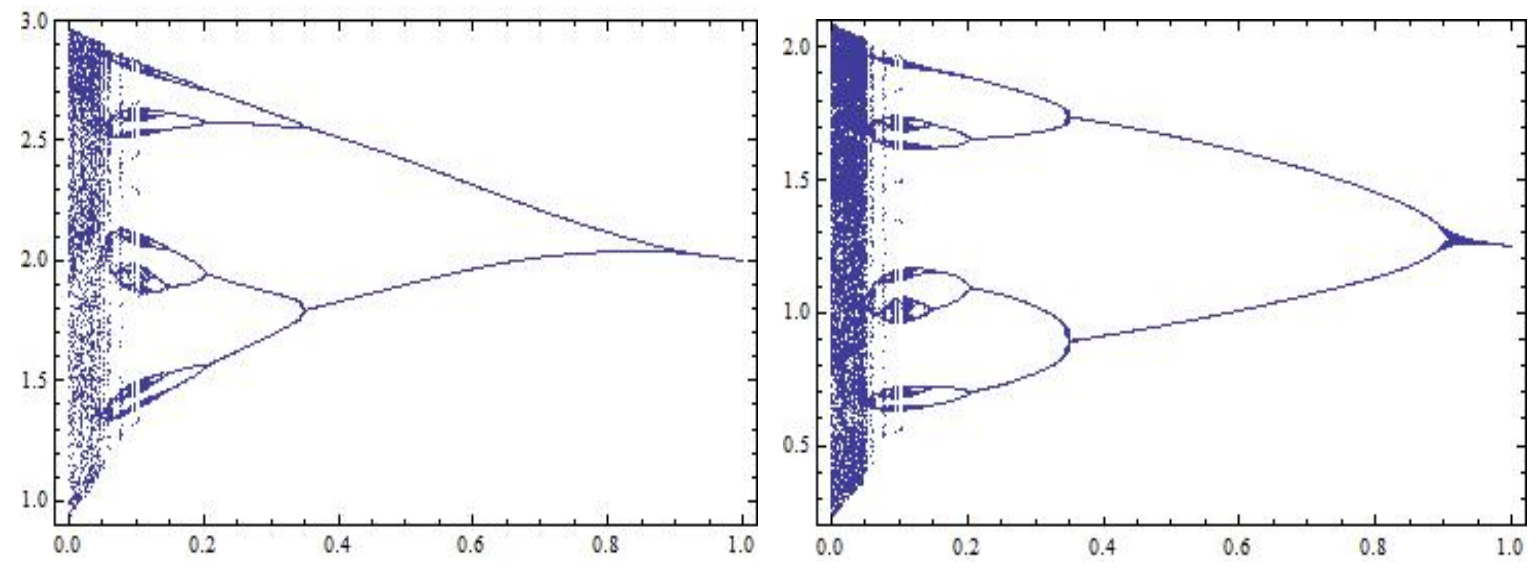

Figure 14. Two bifurcation diagrams of Fig.13 are plotted in one.

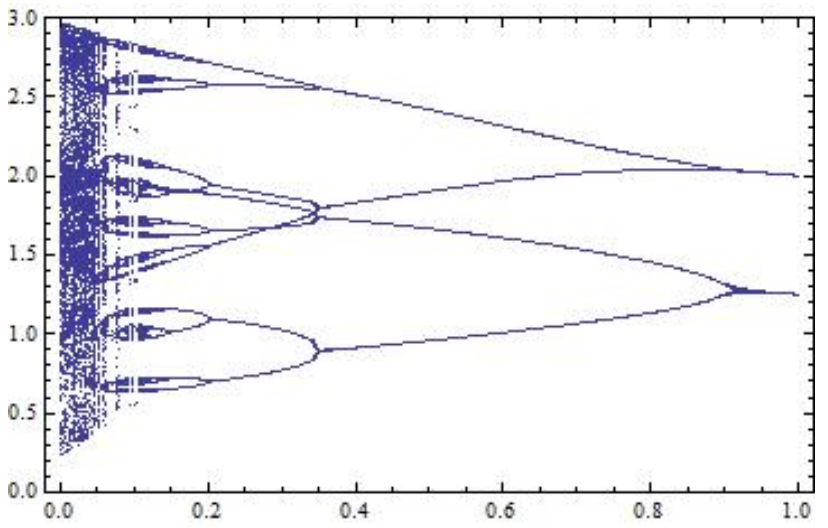


These figures show that the equilibrium undergoes a flip bifurcation at $\mu=0.95$. A strange attractor for $\mu=0.04$ is visualized also in Figure 15 (left). This is the graph of the orbit of $(0.1,0.1)$ with 8000 iterations of the map Eq. (13) for $\mathrm{a}=5, \mathrm{c}=1, \mathrm{~d}=-0.6$ and $\mathrm{k}=0.39$. Figure 15 (right) shows the Lyapunov numbers of the same orbit.

Figure 15. Phase portrait (strange attractor) (left) and Lyapunov numbers (right) of the orbit of $(0.1,0.1)$ with 2000 iterations of the map Eq. (13) for $a=5$, $c=1, k=0.39, d=-0.6$ and $\mu=0.04$
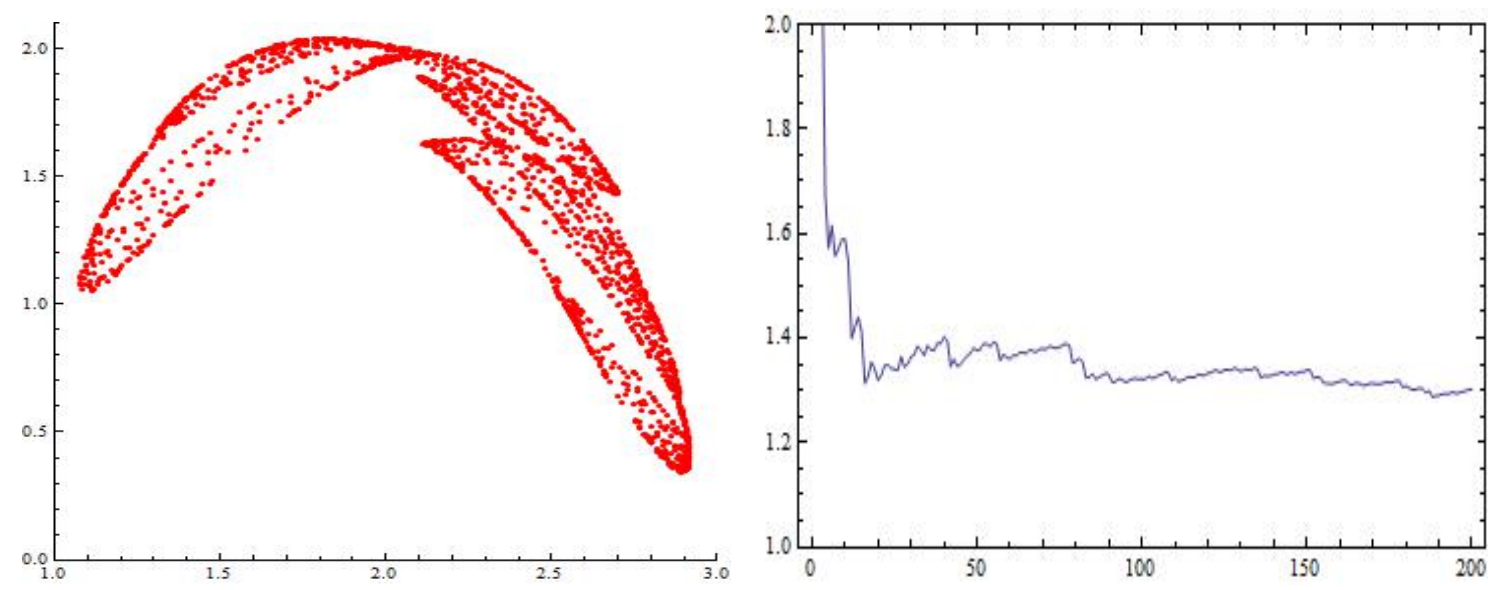

Also, this behaviour has the characteristic sensitivity of this system on its initial conditions for the same values of these parameters (Figure 16).

Figure 16. Sensitive dependence on initial conditions for $q_{1-}$ - coordinate plotted against the time: the orbit of $(0.1,0.1)$ (left) and the orbit of $(0.101,0.1)$ (right) of the system Eq. (13) for $a=5, c=1, k=0.39, d=-0.6$ and $\mu=0.04$
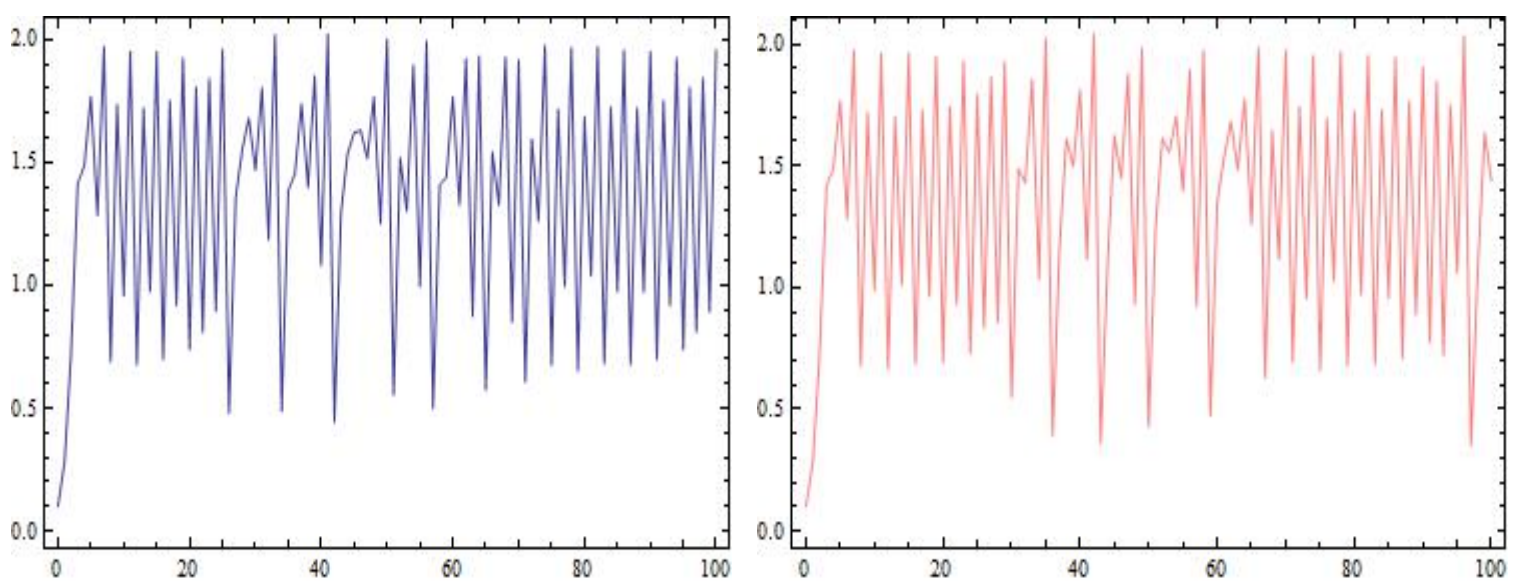

\section{Conclusion}

In this paper, we investigated the complex features behind quantity competition using generalized relative profit functions. For this purpose, we analysed the dynamics of a differentiated Cournot duopoly with homogeneous expectations, linear demand and asymmetric cost functions. By assuming that at each time period each firm maximizes its expected relative profit under bounded rationality expectation, a discrete dynamic system 
was obtained. Existence and stability of equilibrium of this system are studied. We showed numerically that the model gives chaotic and unpredictable trajectories. The main result is that a lower degree of product differentiation, a lower value of the relative profit parameter and a high value of the speed of adjustment may destabilize the Cournot-Nash equilibrium. But we showed also that for lower values of the speed of adjustment the equilibrium is stable for each value of the differentiation parameter or the relative profit parameter. Finally, we find that in the presence of substitute goods there are stable trajectories for each value of the relative profit parameter. This work is a part of the theoretical framework of a broader research objective which is the study of a duopoly in the Greek market and the control of this complexity.

Acknowledgments: We would like to thank the referees for valuable comments and suggestions that greatly help us to improve this paper.

\section{References:}

Agiza, H.N. (1999): On the analysis of stability, bifurcation, chaos and chaos control of Kopel map. Chaos, Solitons \& Fractals 10: 1909-1916.

Agiza, H.N., Elsadany, A.A., (2003): Nonlinear dynamics in the Cournot duopoly game with heterogeneous players. Physica A 320: 512-24.

Agiza, H.N., Elsadany, A.A. (2004): Chaotic dynamics in nonlinear duopoly game with heterogeneous players. Appl. Math. Comput. 149: 843-60.

Agiza, H.N., Hegazi, A.S., Elsadany, A.A. (2002): Complex dynamics and synchronization of duopoly game with bounded rationality. Math. Comput. Simulat 58: 133-46.

Agliari, A., Gardini, L., Puu, T. (2005): Some global bifurcations related to the appearance of closed invariant curves. Mathematics and Computers in Simulation, 68: 201-219.

Agliari, A., Gardini, L., Puu, T. (2006): Global bifurcations in duopoly when the Cournot point is destabilized via a subcritical Neimark bifurcation. International Game Theory Review, 8: 1-20.

Askar, S.S. (2013): On complex dynamics of monopoly market, Economic Modelling, 31: 586-589.

Askar, S.S. (2014): Complex dynamic properties of Cournot duopoly games with convex and logconcave demand function, Operations Research Letters 42: 85-90.

Baumol, W.J., Quandt, R.E. (1964): Rules of thumb and optimally imperfect decisions, American Economic Review 54 (2): 23-46.

Bischi, G.I., Kopel, M. (2001): Equilibrium selection in a nonlinear duopoly game with adaptive expectations. J. Econom Behav. Org. 46: 73-100.

Cournot, A. (1963): Researches into the mathematical principles of the theory of wealth. Homewood (IL): Irwin.

Den Haan, W.J. (2001): The importance of the number of different agents in a heterogeneous assetpricing model. J. Econom. Dynam. Control, 25:721-46.

Elsadany A.A. (2017): Dynamics of a Cournot duopoly game with bounded rationality based on relative profit maximization. Applied Mathematics and Computation 294: 253-263.

Elaydi, S., (2005): An Introduction to Difference Equations, third ed., Springer-Verlag, New York. Fanti, L., Gori, L. (2012): The dynamics of a differentiated duopoly with quantity competition. Economic Modelling, 29: 421-427.

Hommes, C.H., (2006): Heterogeneous agent models in economics and finance, in: L. Tesfatsion, K.L. Judd (Eds.): Handbook of Computational Economics, Agent-Based Computational Economics, vol. 2, Elsevier Science B.V: 1109-1186.

Gandolfo G. (1997): Economic dynamics. Berlin: Springer. 
Kopel, M. (1996): Simple and complex adjustment dynamics in Cournot duopoly models. Chaos Solitons Fract. 12: 2031-48.

Kulenovic, M., Merino, O. (2002): Discrete Dynamical Systems and Difference Equations with Mathematica, Chapman \& Hall/Crc.

Medio, A, Gallo, G. (1995): Chaotic dynamics: theory and applications to economics. Cambridge (MA): Cambridge University Press.

Medio, A, Lines, M. (2001): Nonlinear dynamics. A primer. Cambridge (MA): Cambridge University Press.

Naimzada, A.K., Ricchiuti, G., (2008): Complex dynamics in a monopoly with a rule of thumb, Applied Mathematics and Computation 203: 921-925.

Naimzada, A., Sbragia, L., (2006): Oligopoly games with nonlinear demand and cost functions: two boundedly rational adjustment processes, Chaos Solitons Fractals, 29: 707-722.

Puu, T. (1995): The chaotic monopolist, Chaos, Solitons \& Fractals, 5 (1): 35-44.

Puu, T. (1998): The chaotic duopolists revisited. J Econom. Behav. Org. 37: 385-94.

Sarafopoulos, G. (2015a): On the dynamics of a duopoly game with differentiated goods, Procedia Economics and Finance, 19: 146 - 153.

Sarafopoulos, G. (2015b): Complexity in a duopoly game with homogeneous players, convex, log linear demand and quadratic cost functions, Procedia Economics and Finance, 33: 358 - 366.

Sarafopoulos, G., Papadopoulos, K. (2017): On a Cournot duopoly game with differentiated goods, heterogeneous expectations and a cost function including emission costs, Scientific Bulletin Economic Sciences, 1(1): 11-22.

Sarafopoulos, G., Papadopoulos, K. (2018): On the stability of a Cournot dynamic game under the influence of information, Knowledge E Publishing, ISSN: 2518-668X, 131-144.

Sarafopoulos, G., Papadopoulos, K. (2019a): Chaos in oligopoly models, International Journal of Productivity Management and Assessment Technologies, 7(1): 50-76.

Sarafopoulos, G., Papadopoulos, K., (2019b): Complexity in Bertrand duopoly game with heterogeneous players and differentiated goods, Economic and Financial Challenges for Eastern Europe, Article 2 (p. 15-26), Springer.

Satoh, A., Tanaka, Y. (2014): Relative Profit Maximization and Equivalence of Cournot and Bertrand Equilibria in Asymmetric Duopoly, MPRA Paper no. 56031. Online at http://mpra.ub.unimuenchen.de/56031/

Sedaghat, H. (2003): Nonlinear Difference Equations: Theory with Applications to Social Science Models, Kluwer Academic Publishers (now Springer).

Tramontana, F. (2010): Heterogeneous duopoly with isoelastic demand function. Economic Modelling, 27: 350-357.

Zhang, J., Da, Q., Wang, Y., (2007): Analysis of nonlinear duopoly game with heterogeneous players. Economic Modelling, 24:138-148. 